\title{
The role of astrocyte-secreted matricellular proteins in central nervous system development and function
}

\author{
Cagla Eroglu
}

Received: 19 June 2009 / Accepted: 1 October 2009 / Published online: 11 November 2009

(C) The Author(s) 2009. This article is published with open access at Springerlink.com

\begin{abstract}
Matricellular proteins, such as thrombospondins (TSPs1-4), SPARC, SPARC-like1 (hevin) and tenascin C are expressed by astrocytes in the central nervous system (CNS) of rodents. The spatial and temporal expression patterns of these proteins suggest that they may be involved in important developmental processes such as cell proliferation and maturation, cell migration, axonal guidance and synapse formation. In addition, upon injury to the nervous system the expression of these proteins is upregulated, suggesting that they play a role in tissue remodeling and repair in the adult CNS. The genes encoding these proteins have been disrupted in mice. Interestingly, none of these proteins are required for survival, and furthermore, there are no evident abnormalities at the gross anatomical level in the CNS. However, detailed analyses of some of these mice in the recent years have revealed interesting CNS phenotypes. Here we will review the expression of these proteins in the CNS. We will discuss a newly described function for thrombospondins in synapse formation in the CNS in detail, and speculate whether other matricellular proteins could play similar roles in nervous system development and function.
\end{abstract}

Keywords Astrocyte · Hevin · SPARC · Synaptogenesis · Tenascin $\cdot$ Thrombospondin

$\begin{array}{ll}\text { Abbreviations } \\ \text { ACM } & \text { Astrocyte conditioned media } \\ \text { Cacna2d1 } & \text { Calcium channel subunit alpha2 delta } 1 \\ \text { CNS } & \text { Central nervous system }\end{array}$

C. Eroglu (西)

Cell Biology, Duke University Medical Center,

333A Nanaline Duke Bldg., Box 3709, Durham, NC 27710, USA

e-mail: c.eroglu@cellbio.duke.edu

$\begin{array}{ll}\text { ECM } & \text { Extracellular matrix } \\ \text { EM } & \text { Electron microscopy } \\ \text { GBP } & \text { Gabapentin } \\ \text { PNS } & \text { Peripheral nervous system } \\ \text { RGC } & \text { Retinal ganglion cell } \\ \text { SPARC } & \text { Secreted Protein Acidic and Rich in Cysteine } \\ \text { Tn-C } & \text { Tenascin C } \\ \text { TSP } & \text { Thrombospondin }\end{array}$

\section{Introduction}

In the peripheral nervous system (PNS), neuromuscular junctions contain a well-defined basal lamina composed of a highly ordered network of extracellular matrix (ECM) proteins such as laminins and collagens. This structure is important for the formation and function of this synapse (Patton 2003). The lack of such an obvious organization of the ECM in the central nervous system (CNS) has led to the misconception that the ECM does not exist in the brain. Therefore, its role in the development and the function of the CNS has been largely neglected. However, many ECM proteins are indeed expressed in the nervous system (Dityatev and Schachner 2006). Among these are the matricellular proteins which do not appear to contribute directly to the structural organization of the ECM, but rather seem to function by modulating cell-cell and cellmatrix interactions (Bornstein 2000). Thrombospondin family members TSPs1-4, SPARC and its homolog SPARC-like 1 (hevin) and tenascin $\mathrm{C}$ are matricellular proteins with interesting spatial and temporal expression patterns in the CNS (Adams and Tucker 2000; Lively and Brown 2008a; Mendis et al. 1995; Vincent et al. 2008). Recent gene expression profiling of different cell types in the brain further showed that the messenger RNAs 
(mRNAs) for these matricellular proteins were mostly enriched in glia and were particularly expressed by developing astrocytes (Table 1, (Cahoy et al. 2008)).

Astrocytes are the most abundant cells in the mammalian brain, however the full extent of their properties and the specific roles they play in the formation and function of the CNS remains to be determined (Barres 2008). Astrocytes are complex process-bearing cells. One astrocyte is estimated to contact thousands of synapses through these intricate processes (Bushong et al. 2002). This close association enables astrocytes to participate actively in synaptic signaling through release and uptake of neurotransmitters and neuroactive substances (reviewed in (Eroglu et al. 2008)). Recognition of this tight structural and functional association of astrocytes with the synaptic cleft led to the redefinition of the compartments of the synapse to include perisynaptic astrocytic process and neuronal pre and postsynaptic specializations, collectively referred to as the tripartite synapse (Araque et al. 1999).

In the developing nervous system, synapse formation is spatiotemporally controlled, suggesting the presence of regulatory mechanisms. For example, the majority of excitatory synapses in the brain form during the second and third postnatal weeks, even though the neuronal maturation and axon path-finding events are mostly completed by birth. This 1-week delay between target innervation by neurons and the establishment of synapses correlates with the appearance and maturation of astrocytes in the brain, which suggests that astrocytes may provide instructive cues that contribute to the initiation of excitatory synapse formation (Ullian et al. 2001; Ullian et al. 2004).

Studies of the role of astrocytes in the mammalian nervous system have been a challenge since glia are crucial for the survival of neurons both in vivo and in vitro (Banker 1980; Craig and Banker 1994; Shaham 2006). As such, neuronal culture systems that are traditionally utilized to study synapse formation contain glia. To circumvent this limitation, Meyer-Franke and colleagues developed a retinal ganglion cell (RGC) culture system that utilizes an immunopanning strategy to purify these neurons with up to $99.9 \%$ homoge- neity from rodent retina (Meyer-Franke et al. 1995). RGCs then can be cultured in a serum-free media of known composition and in the complete absence of glia making this an ideal in vitro model to study the role of astrocytes in synaptic development. Interestingly, an initial analysis of synapse formation and function in these cultures revealed that RGCs do not establish synapses in culture. However when these cells were cultured either in the presence of astroglial feeding layers or astrocyte conditioned media (ACM), RGCs formed many active synapses, suggesting the presence of secreted synaptogenic signals provided by astrocytes (Pfrieger and Barres 1997; Ullian et al. 2001).

\section{Thrombospondins regulate synapse formation in the developing CNS}

To identify the synaptogenic activity present in astrocyteconditioned media (ACM) Christopherson and colleagues screened a list of astrocyte-secreted proteins, including matricellular proteins, such as SPARC, tenascin C, osteopontin and TSP1, for their ability to induce synapse formation. Among the twenty or so candidates tested, only purified TSP1, when added to RGC cultures, significantly increased the number of synapses formed between RGCs, as determined both by immunocytochemistry and electron microscopy (Fig. 1A and B) (Christopherson et al. 2005). TSP1 could increase the synapse number in RGC cultures to a similar degree as ACM, and TSP1's activity was not additive to that of ACMs. These findings suggested that TSP is the synaptogenic factor in astrocytes. TSP2, which is a closely related TSP family member, was also found to induce synapse formation at levels similar to that of TSP1. Christopherson et al. found that TSP2 is the major TSP type in the ACM, and that immunodepletion of TSPs from ACM reduced its synaptogenic effect to control levels. Taken together, these results showed that TSPs are necessary and sufficient components of the synaptogenic activity in ACM (Christopherson et al. 2005).

Table 1 Cellular origin of matricellular protein gene expression in the developing and adult rodent brain. Adapted from data published in (Cahoy et al. 2008)

\begin{tabular}{|c|c|c|c|c|c|}
\hline & Neurons & Early postnatal astrocytes & Adult astrocytes & Cultured astrocytes & Oligodendrocytes \\
\hline TSP1 & Absent & Present & Absent & High & Absent \\
\hline TSP2 & Absent & Present & Absent & High & Absent \\
\hline TSP3 & Absent & Present & Low & High & Present \\
\hline TSP4 & Absent & Absent & Present & Absent & Absent \\
\hline $\mathrm{Tn}-\mathrm{C}$ & Absent & Very High & Present & Present & Absent \\
\hline SPARC & Absent & High & Present & Very High & Low \\
\hline Hevin/SPARC like1 & Present & Very High & Very High & High & Low \\
\hline
\end{tabular}


A
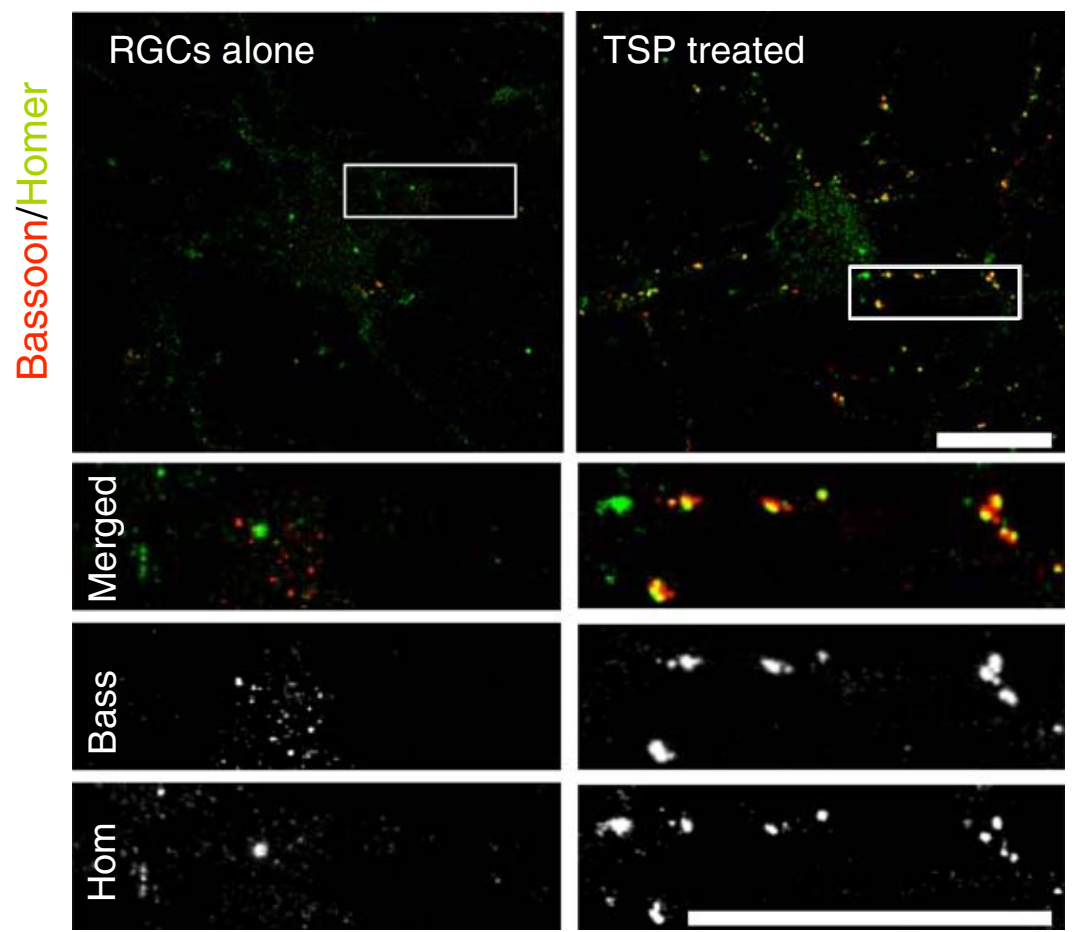

B
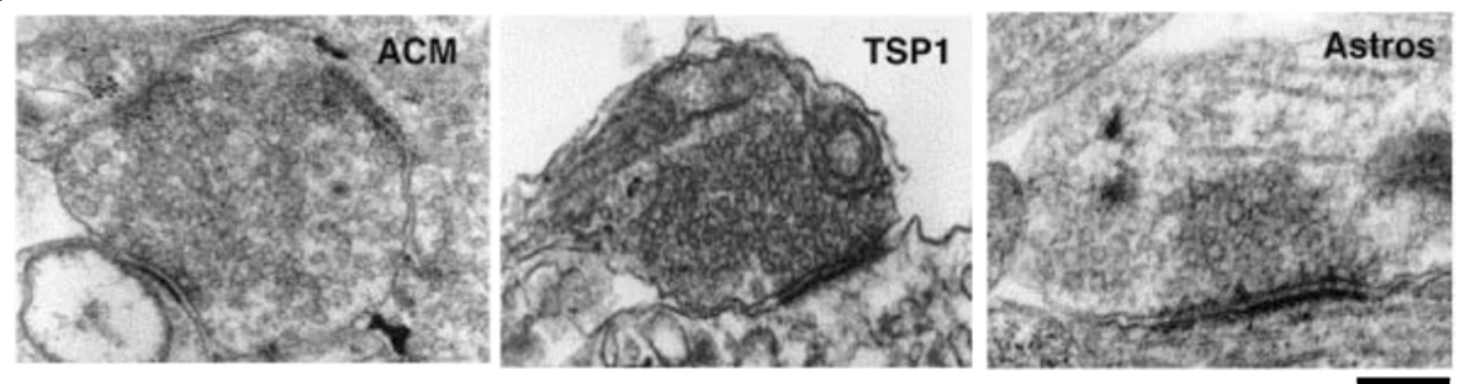

C

wt

TSP1/2 KO
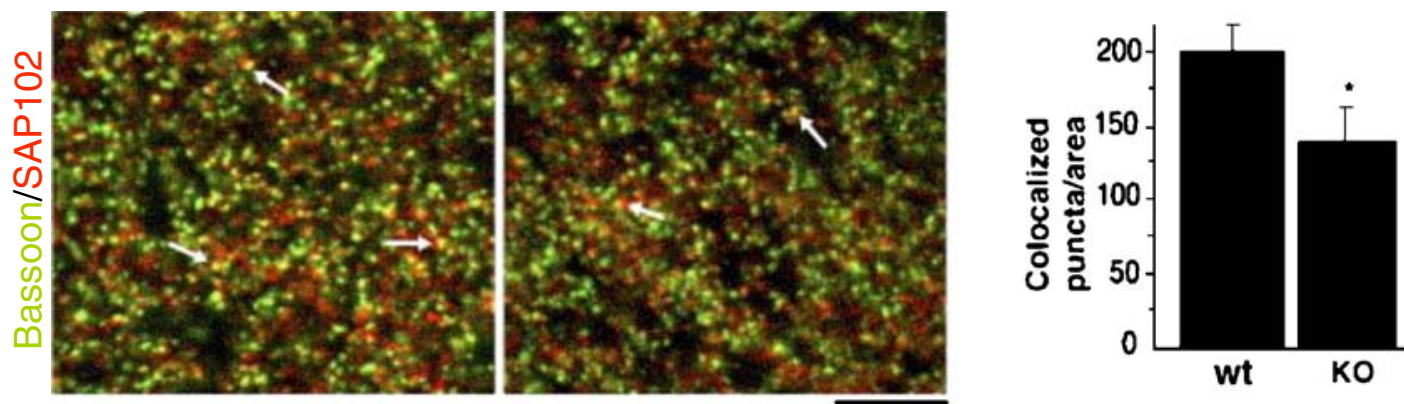

Fig. 1 Thrombospondins induce CNS synapse formation: A RGCs, when cultured alone do not form many synapses (left). On the contrary, RGCs cultured in the presence of purified TSP form many synapses, which are visualized by the co-localization of the presynaptic marker bassoon (red) and the post-synaptic marker, homer (green). Scale bar $30 \mu \mathrm{m}$. B TSP-induced synapses are ultrastructurally normal (middle), with pre- and post- synaptic structures that are similar to the synapses induced by astrocytes (Astros) or ACM. Images taken from (Christopherson et al. 2005). Scale bar $500 \mathrm{~nm}$. Reproduced with permission from Cell Press. C TSP1/2 double KO animals have a reduced number of cortical synapses. WT and KO brains were co-stained for the pre-synaptic marker, Bassoon (green) and postsynaptic marker SAP102 (red). The number of co-localized synaptic puncta was significantly lower in TSP $1 / 2 \mathrm{KO}$ when compared to WTs. White arrows show examples of co-localized synaptic puncta. Quantification of co-localized puncta showed a $25-30 \%$ decrease in the number of synapses in the KO mice. Image taken from (Christopherson et al. 2005). Scale bar $6 \mu \mathrm{m}$. Reproduced with permission from Cell Press 
Christopherson et al. also showed that TSP-induced synapses are ultrastructurally normal, with pre- and postsynaptic specializations similar to those observed in RGC cultures grown with an astrocyte feeding layer (as determined by EM, Fig. 1B). TSP-induced synapses were also presynaptically active, since synaptic vesicles were cycling, which was determined by lipophilic FM-dye uptake and release analysis. However electrophysiological analysis showed that TSP-treated cells formed postsynaptically inactive (silent) synapses. This lack of postsynaptic activity was due to the absence of glutamate receptors in the postsynaptic membrane (Christopherson et al. 2005). This discovery suggested the presence of at least two steps in the establishment of CNS synapses that are regulated by astrocytes (Ullian et al. 2004). The first step is the establishment of a synaptic adhesion that leads to the recruitment of pre- and postsynaptic specializations. This step can be induced by TSPs. The second step is the insertion of glutamate receptors into the postsynaptic site, which is mediated by an as of yet unknown astrocytic signal. Interestingly, the conversion from silent to active synapses by increasing glutamate receptors at the synapse is a mechanism also observed during developmental synaptic maturation and following the induction of long-term potentiation (Freeman 2005; Liao et al. 1995, 2001). Whether there are other matricellular proteins that are synaptogenic and control different steps of synapse formation, maturation and synaptic plasticity is an area for future research.

In addition to the in vitro results of the synaptogenic activity of TSP1 and TSP2, Christopherson and colleagues showed that TSP1 and 2 are necessary for synapse formation in vivo by analyzing the number of synapses in the cortices of TSP $1 / 2$ double-null mice. These mice have a $25-30 \%$ reduction in the number of excitatory synapses formed in their cortices during first and third postnatal weeks (Fig. 1C). It is not yet known whether the synaptic defects seen in TSP $1 / 2$ double null-mice are specific to cortical excitatory synapses only or whether TSPs are also required for excitatory synapse formation in other parts of the CNS. Taken together, the results of this study identify TSPs as the key synaptogenic signal coming from astrocytes in culture, and that loss of TSP $1 / 2$ function in mice significantly decreased synapse formation during development (Christopherson et al. 2005).

Earlier studies exploring TSP1-2 expression during embryonic and postnatal development have shown that TSP protein expression can be detected in the neural plate as early as E8.5 and is present all through CNS development (O'Shea and Dixit 1988; O'Shea et al. 1990a, b). TSP expression in the CNS dramatically decreases in the adult rodent CNS and becomes restricted to areas of neurogenesis and plasticity (Hoffman et al. 1994). Interestingly, in the nervous systems of organisms with enhanced regenerative capacity, such as newt and goldfish, TSP expression stays high even in the adult (Hoffman and O'Shea 1999a; Hoffman and O'Shea 1999b). In agreement with these earlier studies, Christopherson and colleagues detected TSP $1 / 2$ protein expression in cortical lysates from an early postnatal age (P5) that corresponds with the initiation of the synaptogenic period, but not in the adult cortex (Christopherson et al. 2005). Gene expression analysis of cortical CNS cell types further showed that TSP1 and 2 mRNAs are expressed by acutely isolated early postnatal astrocytes from mouse cerebral cortex as well as in astroglial cultures but are downregulated in mature astrocytes (P17) (Table 1, ((Cahoy et al. 2008)).

Besides TSPs 1 and 2, other TSPs (TSP3-5) are also found in mammals (Adams and Lawler 2004). Astrocytes express mRNA for TSP3 and 4. In contrast to other TSPs, TSP4 expression is only detected in mature astrocytes (after P17, Table 1 (Cahoy et al. 2008). TSP4 could represent the adult isoform of TSP in the CNS important for the control synaptogenesis and synaptic plasticity in the adult brain. Interestingly, TSP4 is also present in the neuromuscular junction, suggesting a function for TSPs in neuromuscular junction formation (Arber and Caroni 1995). Recent work comparing gene expression patterns in brains of humans and other primates turned the spotlight on TSPs. In humans, TSP2 and TSP4 expression levels are dramatically increased (Caceres et al. 2007). Though speculative, these results raise the question of whether higher TSP expression levels provides the human brain with a greater capacity to form synapses, and thus enhance human cognitive functions, compared to those of other primates.

How do TSPs promote synapse formation? Since TSPs mediate a wide range of functions in modulating cell-cell and cell-matrix interactions via interacting with cell surface receptors (Bornstein et al. 2004), it was postulated that TSP induces synapse formation via interacting with a neuronal receptor and that this interaction is required for the initiation of an axodendritic synaptic contact (Christopherson et al. 2005). A number of known TSP receptors are expressed by neurons, however, Eroglu and colleagues found that none of the known TSP receptors were involved in the synaptogenic activity of TSP (Eroglu et al. 2009). Instead they identified a novel interaction partner for TSPs, namely the non-pore-forming auxiliary subunit of calcium channels $\alpha 2 \delta-1$, to be the TSP receptor involved in synapse formation. Synapse formation by TSPs is mediated through an interaction between the epidermal growth factor-like repeats of TSPs and the von-Willebrand factor A likedomain of $\alpha 2 \delta-1$. Overexpression of $\alpha 2 \delta-1$ in RGCs enhances TSPs' ability to induce synapse formation. Furthermore, siRNA knockdown of $\alpha 2 \delta-1$ revealed that $\alpha 2 \delta-1$ is necessary for TSP-induced synapse formation in vitro. The role of $\alpha 2 \delta-1$ in synapse formation is not 
dependent on its known roles in calcium channel function and trafficking, suggesting that this molecule might have other functions in the cell that do or do not involve calcium channels. In agreement with in vitro findings, over expression of $\alpha 2 \delta-1$, specifically in neurons, in a transgenic mouse line, results in a significant increase in the number of excitatory synapses in vivo (Eroglu et al. 2009).

In addition to binding TSPs, $\alpha 2 \delta-1$ is a known target for the anti-convulsant, anti-neuropathic pain drug Gabapentin (GBP) which is known to mediate its therapeutic function through this interaction (Field et al. 2006). GBP blocked TSP- $\alpha 2 \delta-1$ interaction and astrocyte/TSP-induced synapse formation in vitro (Eroglu et al. 2009). In addition, GBP injection into neonatal mice during the first postnatal week led to a very severe reduction in the number of excitatory synapses, which was as low as ten percent of control levels in half of GBP-injected animals (Eroglu et al. 2009). The magnitude of reduction seen in this study far exceeded that seen in TSP1/2 double KOs (Christopherson et al. 2005), suggesting that that TSP3 and 4 might partially compensate for the loss of TSP1 and 2 in the KOs. The ability of GBP to strongly decrease synapse formation in the brains of wild-type mice points to a critical role for TSP- $\alpha 2 \delta-1$ interactions in driving synaptogenesis in vivo. In summary these findings add to the growing data showing that astrocytes and the TSPs they release contribute to synapse formation in the developing brain, and identify $\alpha 2 \delta-1$ as a new molecule that regulates synapse formation. Future research investigating how the TSP- $\alpha 2 \delta-1$ interaction leads to synapse formation is necessary to understand the intracellular signaling molecules and mechanisms that govern the process of synapse formation in the CNS.

$\alpha 2 \delta-1$ is also expressed at high levels outside the CNS, in tissues including skeletal and cardiac muscles and bone (Arikkath and Campbell 2003). Extensive previous research on TSP function has been performed in these non neuronal tissues, therefore, it will be interesting to explore in the future whether the TSP- $\alpha 2 \delta-1$ interaction is also involved in some of the known functions of TSP in these tissues.

\section{Thrombospondins are involved in synaptic remodeling after injury}

It is a recurring theme for many matricellular proteins, including TSPs, that upon injury to the nervous system their expression is upregulated. For example the levels of TSPs 1 and 2 are increased after a stroke (Lin et al. 2003). Purinergic signaling and mechanical stimulation have been shown to play a role in TSP upregulation in astrocytes (Tran and Neary 2006). Liauw and colleagues investigated whether TSP $1 / 2$ were required for synaptic and functional recovery after strokes (Liauw et al. 2008). To do so, they induced focal ischemia in 8- to 12-week-old wild-type (WT) and TSP-1/2 double knockout (TSP1/2 KO) mice by unilateral occlusion of the distal middle cerebral artery and the common carotid artery. These investigators showed that in WT mice TSP 1 and 2 mRNAs and protein levels were increased. This increase was mostly co-localized with GFAP- positive reactive astrocytes. They compared WT and $\mathrm{KO}$ mice for angiogenesis, synaptic density, axonal sprouting, infarct size, and functional recovery at different time points. TSP-1/2 KO mice exhibited a significant deficit in their ability to recover, particularly in the tongue protrusion test of motor function, when compared with WT mice. Previously, the increase of TSPs after a stroke was postulated to take part in post-ischemic angiogenesis (Lin et al. 2003). However, Liauw and colleagues found no differences in infarct size and blood vessel density between the WT and TSP1/2KO groups, suggesting that angiogenesis was not significantly affected by the lack of TSPs. Instead TSP-1/2 KO mice exhibited significant deficits in synaptic density and axonal sprouting (Liauw et al. 2008). Since a deficiency of TSP- $1 / 2$ leads to impaired recovery after a stroke, mainly due to impaired synapse formation and axonal outgrowth, it is likely that TSPs are involved in a synaptic recovery process after injury in the adult CNS.

Understanding how the brain remodels its neuronal networks is a major goal of neurobiology, as these processes underlie learning, memory and recovery from injury. To determine whether astrocytes and the TSPs they secrete are involved in lesion-induced synaptic remodeling in the developing CNS, Eroglu and colleagues utilized a well-established developmental plasticity paradigm, 'the barrel cortex plasticity' assay (Eroglu et al. 2009). The nerves that innervate the major whiskers on the snout of the mouse project to the brain as a topographically ordered "somatotopic" map where afferent axons and target cells form ordered modules that recapitulate the structural organization of the whisker pad (Erzurumlu et al. 2006). The somatotopic map in the cortex forms a pattern consisting of what are known as "barrels". The barrel cortex exhibits structural changes in its circuitry in response to peripheral whisker manipulations. Thus if a row of whiskers on the snout is lesioned during a critical period of postnatal development (the first three postnatal days in mice), the corresponding barrels in the cortex shrink and fuse, while axons that innervate the neighboring barrels invade the territory vacated by projections from the lesioned whiskers (Van der Loos and Woolsey 1973). Interestingly, inhibition of TSP-mediated synapse formation, either by injection of GBP or by the use of TSP1/2deficient mice, led to extensive outgrowth of the intact afferents that extended beyond the affected region. These manipulations caused barrels to lose form and fuse in 
varying degrees, a phenotype which was never observed in saline-injected or wild-type mice (Eroglu et al. 2009). These findings suggest that astrocyte-secreted TSPs induce the synapse formation required for rewiring of barrels following injury. Blocking TSP-induced synapse formation may lead to the loss of a "stop and connect" signal such that the axons continue to search for an appropriate target, resulting in the inability to reform barrels correctly. Interestingly, neither the GBP-injected mice nor the TSP1/ $2 \mathrm{KO}$ mice had problems in the normal establishment of the barrels in the unlesioned control hemisphere, suggesting that TSPs specifically play a role in synaptic remodelingplasticity upon injury in this system. It is possible that a whisker lesion-dependent upregulation of TSPs, or their neuronal receptor $\alpha 2 \delta 1$, might be necessary to mediate this function.

In fact an increase in $\alpha 2 \delta-1$ levels after injury has been demonstrated to occur in the spinal nerve ligation model of neuropathic pain (Li et al. 2004). Interestingly, TSP4 levels also increase in this pain model (Valder et al. 2003). Together, these data suggest that the increase in the expression levels of $\alpha 2 \delta-1$ and TSPs could be an essential part of the synaptic remodeling in response to synapse loss following injury. In addition, since GBP is a drug against neuropathic pain and is able to block the TSP- $\alpha 2 \delta-1$ interaction and resulting synapse formation, it is possible that its therapeutic function includes the inhibition of excess synapse formation induced by upregulation of these molecules after injury to the CNS. These findings also highlight TSPs as potential drug targets for diseases such as neuropathic pain and epilepsy.

\section{Other astrocyte-secreted matricellular proteins in the CNS}

\section{Tenascin C}

Tenascin $\mathrm{C}$ (Tn-C) is highly expressed by astrocytes at early stages of the development of the CNS while its expression is strongly reduced in the adult CNS (Bartsch et al. 1992). However in the mature CNS, Tn-C is still expressed by specific cell populations, notably those in close proximity to areas of active neurogenesis, such as the hippocampus, subventricular zone borders and the rostral migratory stream (Bartsch et al. 1992; Bartsch et al. 1994; Gates et al. 1995; Jankovski and Sotelo 1996). These expression patterns suggest important roles for $\mathrm{Tn}-\mathrm{C}$ in the remodeling of the CNS, both during development and in the adult. Studies using either neuron or glial cultures have revealed that Tn-C can alter CNS cell behavior significantly, often in a cell type-specific manner. For example, Tn-C has been reported to promote axon outgrowth and modulate growth cone dynamics, as well as to inhibit the migration of oligodendrocyte precursor cells and stimulate granule cell migration (Crossin 1994; Faissner and Steindler 1995; Husmann et al. 1995; Kiernan et al. 1996).

Given Tn-C's extensive expression and its strong effects in cell culture, the observation that Tn-C-null mice show no obvious abnormalities was very surprising and suggested redundancy of Tn-C function (Erickson 1993). However, later studies have revealed behavioral abnormalities and alterations in neurotransmitter levels in the adult CNS (Fukamauchi et al. 1996; Kiernan et al. 1999), in a genetic background-dependent manner. A homolog of Tn-C, Tenascin R (janusin), is also expressed in CNS, mainly by oligodendrocyte lineage cells (Bartsch et al. 1993; Jung et al. 1993), and might compensate for lack of Tn-C in the CNS. Another possibility is that $\mathrm{Tn}-\mathrm{C}$ and other matricellular proteins have specific and important roles during early stages of development, but that later developmental processes are able to correct for the loss of this matricellular protein.

In support of this possibility, analyses of the developing CNS in Tn-C knockout mice revealed contributions of Tn-C that were not apparent in the adult brain. These studies confirmed the role of Tn-C in the cell migration of oligodendrocyte precursors, and demonstrated novel roles for $\mathrm{Tn}-\mathrm{C}$ in the regulation of neural precursor cell proliferation (Garcion et al. 2001). Interestingly, reduced levels of programmed cell death were observed in Tn-C KO mice which may have provided a corrective mechanism that accounted for the grossly normal phenotype (Garcion et al. 2001). Recent evidence also suggested that $\mathrm{Tn}-\mathrm{C}$ contributes to the generation of a stem cell niche within the subventricular zone that acts to orchestrate growth factor signaling so as to accelerate neural stem cell development (Garcion et al. 2004).

In a recent study Irintchev and colleagues found that there was abnormally high neuronal density, astrogliosis and reduced density of parvalbumin-positive interneurons in the somatosensory and motor cortices of adult $\mathrm{Tn}-\mathrm{C} \mathrm{KO}$ compared to those of wild-type mice (Irintchev et al. 2005). The ratios of oligodendrocytes to neurons and of inhibitory to excitatory neurons were reduced in the KOs as opposed to in WT animals. Interestingly, layer V pyramidal neurons in the Tn-C KO animals were found to have abnormal dendritic morphology and abnormal distribution of stubby spines suggesting roles for $\mathrm{Tn}-\mathrm{C}$ in regulation of neurite outgrowth and spinogenesis in vivo. Significantly enhanced responses to whisker stimulation were recorded in the barrel and in the motor cortices of KO mice compared to WT animals. The authors suggested that the increased excitation observed in these mice is most likely due to a reduction in inhibitory neuronal signaling (Irintchev et al. 2005). It is possible that part of the phenotypes observed in Tn-Cdeficient mice could be due to the lack of expression of this protein, not only in astrocytes or other glia, but also in 
neurons. Taken together, these studies suggest that Tn-C is critical for determination of neuronal cell-fate and for cell migration and maturation in the developing CNS.

\section{SPARC (osteonectin) and Hevin (SPARC-like 1)}

Similar to Tn-C, SPARC and its close homolog, hevin, are highly expressed in the developing CNS. Early postnatal expression of SPARC is mostly restricted to radial glial cells, and this expression seems to subside with development, coinciding with the disappearance of radial glia (Vincent et al. 2008). In the adult CNS, SPARC expression is enriched in specialized radial glial derivatives, including the Müller glia of the retina and the Bergmann glia of the cerebellum. SPARC is also expressed by blood vessels, and by some cells along the rostral migratory stream, which are restricted to the subventricular zone in adulthood (Fig. 2A) (Vincent et al. 2008). Astrocytes and Schwann cells also secrete SPARC both in vivo and in vitro (Bampton et al. 2005; Mendis et al. 1995) and Schwann cell-secreted

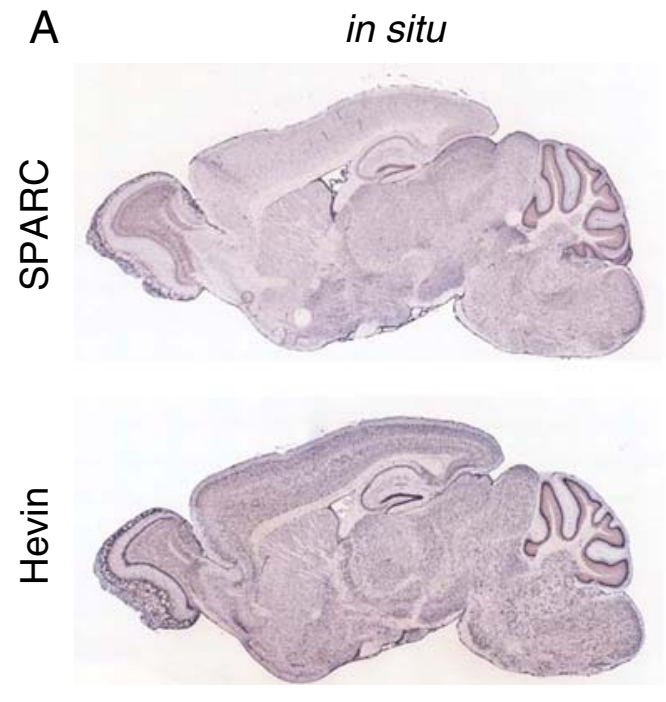

B

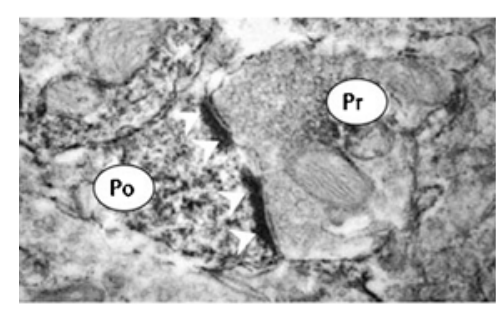

Fig. 2 SPARC and Hevin expression in the adult brain. A In situ analysis of SPARC and hevin expression in 55 day-old mouse brain. Images are from Allen Brain Atlas (Allen Atlas Portal [Internet]. Seattle (WA): Allen Institute for Brain Science. (C2009. Available from: http://www.brain-map.org). Expression analysis (right) is a heat map for intensity of the in situ signal (right). Blue $=$ Low, Orange $=$ High. Scale bar $1 \mathrm{~mm}$. B Hevin is present in CNS synapses and on perisynaptic astrocytic processes. Electron microscopic immunocyto-
SPARC was shown to promote retinal ganglion cell survival and neurite outgrowth (Bampton et al. 2005).

Of the matricellular proteins discussed in this review, hevin's expression in the CNS is perhaps the strongest. Hevin's expression increases during early postnatal development, coinciding well with the synaptogenic period and stays high in the adult brain (Lively et al. 2007; Lively and Brown 2008a; Mendis et al. 1994, 1996b) (Fig. 2A). Hevin mRNA is expressed by almost all cell types in the brain, but the levels in astrocytes are extremely high when compared to that of any other cell type (Table 1, (Cahoy et al. 2008)). One interesting feature of hevin is that it was initially identified as a component of synaptosomes and named synaptic cleft protein 1 (SC1) (Johnston et al. 1990). Later EM immunolabeling studies confirmed that hevin is concentrated at synaptic junctions, as well as along the astrocytic processes that surround synapses (Fig. 2B, (Lively et al. 2007; Lively and Brown 2008a)). Therefore hevin is a prime candidate for future studies of the role of astrocyte-secreted proteins in synapse formation and function.
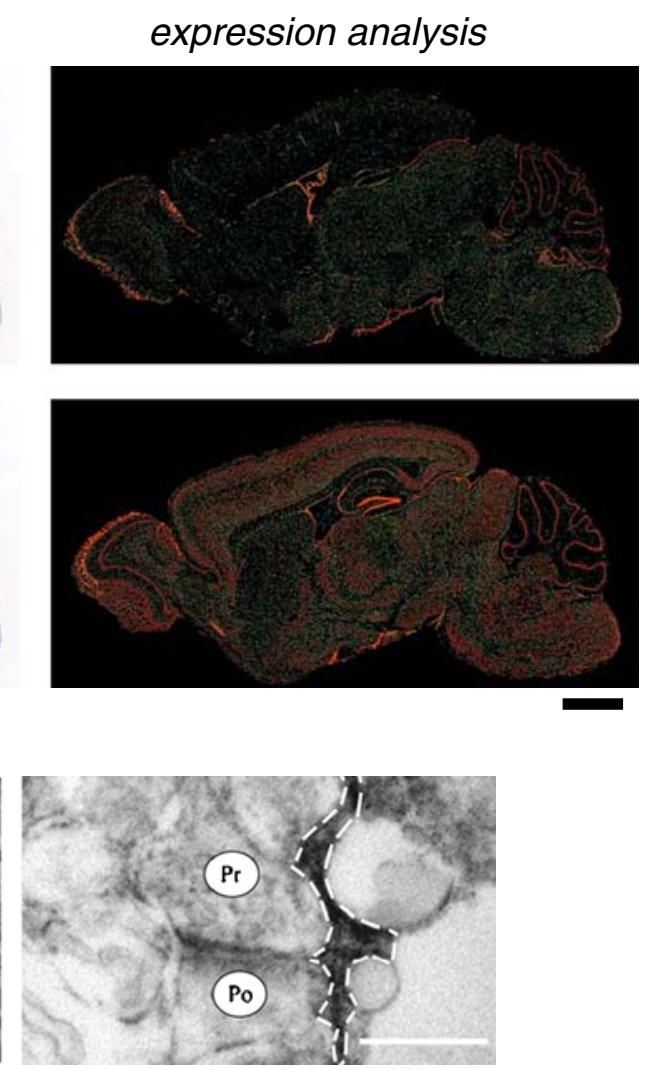

chemistry was performed on the adult rat cerebral cortex. (Left). Hevin protein localizes to synapses in the adult rat brain. Hevin staining was observed in the synaptic cleft closely associated with the postsynaptic element. $\mathrm{Po}=$ postsynaptic, $\mathrm{Pr}=$ presynaptic. White arrows point to synapses. (Right) Hevin staining was also present on perisynaptic astrocyte processes outlined by dashed lines. Scale bar $250 \mathrm{~nm}$. Images from (Lively et al. 2007). Reproduced with permission from Springer Netherlands 
Similar to TSP1/2 and Tn-C-deficient mice, SPARC and Hevin nulls are viable and do not display any gross abnormalities (Bassuk et al. 1999; Gilmour et al. 1998; McKinnon et al. 2000). However, SPARC-null mice develop severe lens degeneration in adulthood (Bassuk et al. 1999; Gilmour et al. 1998). Future detailed physiological and behavioral studies are needed to uncover the roles these proteins play in the development and maintenance of the nervous system.

Like TSPs, hevin and SPARC expression is also upregulated after injury to the CNS, correlating with the onset of reactive gliosis (Liu et al. 2005; Lively and Brown 2007, 2008b; McKinnon and Margolskee 1996; Mendis et al. 1996a, 1998, 2000). SPARC is highly expressed in human gliomas and the protein promotes glioma invasion. In addition, SPARC delays tumor growth in vitro and in vivo, which reveals the molecule as a potential antitumorigenic drug target (Menon et al. 2000; Schultz et al. 2002).

\section{Conclusions}

Matricellular proteins TSP1-4, Tn-C, SPARC, and hevin are expressed mainly by astrocytes in the CNS. They serve important roles both in vitro and in vivo in neuronal cell development, migration and in the establishment of synaptic connections. The expression of these proteins is upregulated in disease conditions and in response to injury to the CNS suggesting a role for these proteins in CNS repair mechanisms. Future studies will determine whether matricellular proteins other than TSPs are involved in synapse formation, function and plasticity.

Acknowledgments I thank Drs Barres and Cahoy (Stanford University) for sharing data relating to the analysis of gene expression of major brain cell types, which were used to prepare Table 1, Dominic Ippolito for critical reading of the manuscript, and Laura Conatser for excellent technical assistance with the preparation of the synaptic staining presented in Fig. 1A. I would like to thank Dr Shanna Arnold (UT Southwestern) for her help with Endnote.

Competing interests The author declares that she has no competing interests.

Open Access This article is distributed under the terms of the Creative Commons Attribution Noncommercial License which permits any noncommercial use, distribution, and reproduction in any medium, provided the original author(s) and source are credited.

\section{References}

Adams JC, Tucker RP (2000) The thrombospondin type 1 repeat (TSR) superfamily: diverse proteins with related roles in neuronal development. Dev Dyn 218:280-299
Adams JC, Lawler J (2004) The thrombospondins. Int J Biochem Cell Biol 36:961-968

Araque A, Parpura V, Sanzgiri RP, Haydon PG (1999) Tripartite synapses: glia, the unacknowledged partner. Trends Neurosci 22:208-215

Arber S, Caroni P (1995) Thrombospondin-4, an extracellular matrix protein expressed in the developing and adult nervous system promotes neurite outgrowth. J Cell Biol 131:1083-1094

Arikkath J, Campbell KP (2003) Auxiliary subunits: essential components of the voltage-gated calcium channel complex. Curr Opin Neurobiol 13:298-307

Bampton ET, Ma CH, Tolkovsky AM, Taylor JS (2005) Osteonectin is a Schwann cell-secreted factor that promotes retinal ganglion cell survival and process outgrowth. Eur J Neurosci 21:2611-2623

Banker GA (1980) Trophic interactions between astroglial cells and hippocampal neurons in culture. Science 209:809-810

Barres BA (2008) The mystery and magic of glia: a perspective on their roles in health and disease. Neuron 60:430-440

Bartsch S, Bartsch U, Dorries U, Faissner A, Weller A, Ekblom P et al (1992) Expression of tenascin in the developing and adult cerebellar cortex. J Neurosci 12:736-749

Bartsch U, Pesheva P, Raff M, Schachner M (1993) Expression of janusin (J1-160/180) in the retina and optic nerve of the developing and adult mouse. Glia 9:57-69

Bartsch U, Faissner A, Trotter J, Dorries U, Bartsch S, Mohajeri H et al (1994) Tenascin demarcates the boundary between the myelinated and nonmyelinated part of retinal ganglion cell axons in the developing and adult mouse. J Neurosci 14:4756-4768

Bassuk JA, Birkebak T, Rothmier JD, Clark JM, Bradshaw A, Muchowski PJ et al (1999) Disruption of the Sparc locus in mice alters the differentiation of lenticular epithelial cells and leads to cataract formation. Exp Eye Res 68:321-331

Bornstein P (2000) Matricellular proteins: an overview. Matrix Biol 19:555-556

Bornstein P, Agah A, Kyriakides TR (2004) The role of thrombospondins 1 and 2 in the regulation of cell-matrix interactions, collagen fibril formation, and the response to injury. Int $\mathrm{J}$ Biochem Cell Biol 36:1115-1125

Bushong EA, Martone ME, Jones YZ, Ellisman MH (2002) Protoplasmic astrocytes in CA1 stratum radiatum occupy separate anatomical domains. J Neurosci 22:183-192

Caceres M, Suwyn C, Maddox M, Thomas JW, Preuss TM (2007) Increased cortical expression of two synaptogenic thrombospondins in human brain evolution. Cereb Cortex 17:2312-2321

Cahoy JD, Emery B, Kaushal A, Foo LC, Zamanian JL, Christopherson KS et al (2008) A transcriptome database for astrocytes, neurons, and oligodendrocytes: a new resource for understanding brain development and function. J Neurosci 28:264-278

Christopherson KS, Ullian EM, Stokes CC, Mullowney CE, Hell JW, Agah A et al (2005) Thrombospondins are astrocyte-secreted proteins that promote CNS synaptogenesis. Cell 120:421-433

Craig AM, Banker G (1994) Neuronal polarity. Annu Rev Neurosci 17:267-310

Crossin KL (1994) Functional role of cytotactin/tenascin in morphogenesis: a modest proposal. Perspect Dev Neurobiol 2:21-32

Dityatev A, Schachner M (2006) The extracellular matrix and synapses. Cell Tissue Res 326:647-654

Erickson HP (1993) Gene knockouts of c-src, transforming growth factor beta 1 , and tenascin suggest superfluous, nonfunctional expression of proteins. J Cell Biol 120:1079-1081

Eroglu C, Barres BA, Stevens B (2008) Glia as active paricipants in the development and function of synapses. In: Hell JW, Ehlers MD (eds) Structural and functional organization of the synapse. Springer, New York, pp 683-714

Eroglu C, Allen NJ, Susman MW, O'Rourke NA, Young Park C et al (2009) Gabapentin receptor $\alpha 2 \delta-1$ is a neuronal thrombospondin 
receptor responsible for excitatory CNS synaptogenesis. Cell 139:380-392

Erzurumlu RS, Chen ZF, Jacquin MF (2006) Molecular determinants of the face map development in the trigeminal brainstem. Anat Rec A Discov Mol Cell Evol Biol 288:121-134

Faissner A, Steindler D (1995) Boundaries and inhibitory molecules in developing neural tissues. Glia 13:233-254

Field MJ, Cox PJ, Stott E, Melrose H, Offord J, Su TZ et al (2006) Identification of the alpha2-delta-1 subunit of voltage-dependent calcium channels as a molecular target for pain mediating the analgesic actions of pregabalin. Proc Natl Acad Sci U S A 103:17537-17542

Freeman MR (2005) Glial control of synaptogenesis. Cell 120:292-293

Fukamauchi F, Mataga N, Wang YJ, Sato S, Youshiki A, Kusakabe M (1996) Abnormal behavior and neurotransmissions of tenascin gene knockout mouse. Biochem Biophys Res Commun 221:151156

Garcion E, Faissner A, ffrench-Constant C (2001) Knockout mice reveal a contribution of the extracellular matrix molecule tenascin- $\mathrm{C}$ to neural precursor proliferation and migration. Development 128:2485-2496

Garcion E, Halilagic A, Faissner A, ffrench-Constant C (2004) Generation of an environmental niche for neural stem cell development by the extracellular matrix molecule tenascin C. Development 131:3423-3432

Gates MA, Thomas LB, Howard EM, Laywell ED, Sajin B, Faissner A et al (1995) Cell and molecular analysis of the developing and adult mouse subventricular zone of the cerebral hemispheres. J Comp Neurol 361:249-266

Gilmour DT, Lyon GJ, Carlton MB, Sanes JR, Cunningham JM, Anderson JR et al (1998) Mice deficient for the secreted glycoprotein SPARC/osteonectin/BM40 develop normally but show severe age-onset cataract formation and disruption of the lens. Embo J 17:1860-1870

Hoffman JR, Dixit VM, O'Shea KS (1994) Expression of thrombospondin in the adult nervous system. J Comp Neurol 340:126-139

Hoffman JR, O'Shea KS (1999a) Thrombospondin expression in nerve regeneration I. Comparison of sciatic nerve crush, transection, and long-term denervation. Brain Res Bull 48:413-420

Hoffman JR, O'Shea KS (1999b) Thrombospondin expression in nerve regeneration II. Comparison of optic nerve crush in the mouse and goldfish. Brain Res Bull 48:421-427

Husmann K, Carbonetto S, Schachner M (1995) Distinct sites on tenascin-C mediate repellent or adhesive interactions with different neuronal cell types. Cell Adhes Commun 3:293-310

Irintchev A, Rollenhagen A, Troncoso E, Kiss JZ, Schachner M (2005) Structural and functional aberrations in the cerebral cortex of tenascin-C deficient mice. Cereb Cortex 15:950-962

Jankovski A, Sotelo C (1996) Subventricular zone-olfactory bulb migratory pathway in the adult mouse: cellular composition and specificity as determined by heterochronic and heterotopic transplantation. J Comp Neurol 371:376-396

Johnston IG, Paladino T, Gurd JW, Brown IR (1990) Molecular cloning of SC1: a putative brain extracellular matrix glycoprotein showing partial similarity to osteonectin/BM40/SPARC. Neuron 4:165-176

Jung M, Pesheva P, Schachner M, Trotter J (1993) Astrocytes and neurons regulate the expression of the neural recognition molecule janusin by cultured oligodendrocytes. Glia 9:163-175

Kiernan BW, Gotz B, Faissner A, ffrench-Constant C (1996) Tenascin-C inhibits oligodendrocyte precursor cell migration by both adhesion-dependent and adhesion-independent mechanisms. Mol Cell Neurosci 7:322-335

Kiernan BW, Garcion E, Ferguson J, Frost EE, Torres EM, Dunnett $\mathrm{SB}$ et al (1999) Myelination and behaviour of tenascin-C null transgenic mice. Eur J Neurosci 11:3082-3092
Li CY, Song YH, Higuera ES, Luo ZD (2004) Spinal dorsal horn calcium channel alpha2delta-1 subunit upregulation contributes to peripheral nerve injury-induced tactile allodynia. J Neurosci 24:8494-8499

Liao D, Hessler NA, Malinow R (1995) Activation of postsynaptically silent synapses during pairing-induced LTP in CA1 region of hippocampal slice. Nature 375:400-404

Liao D, Scannevin RH, Huganir R (2001) Activation of silent synapses by rapid activity-dependent synaptic recruitment of AMPA receptors. J Neurosci 21:6008-6017

Liauw J, Hoang S, Choi M, Eroglu C, Choi M, Sun GH et al (2008) Thrombospondins 1 and 2 are necessary for synaptic plasticity and functional recovery after stroke. J Cereb Blood Flow Metab 28:1722-1732

Lin TN, Kim GM, Chen JJ, Cheung WM, He YY, Hsu CY (2003) Differential regulation of thrombospondin-1 and thrombospondin-2 after focal cerebral ischemia/reperfusion. Stroke 34:177-186

Liu X, Ying G, Wang W, Dong J, Wang Y, Ni Z et al (2005) Entorhinal deafferentation induces upregulation of SPARC in the mouse hippocampus. Brain Res Mol Brain Res 141:58-65

Lively S, Brown IR (2007) Analysis of the extracellular matrix protein $\mathrm{SC} 1$ during reactive gliosis in the rat lithium-pilocarpine seizure model. Brain Res 1163:1-9

Lively S, Ringuette MJ, Brown IR (2007) Localization of the extracellular matrix protein $\mathrm{SC} 1$ to synapses in the adult rat brain. Neurochem Res 32:65-71

Lively S, Brown IR (2008a) Localization of the extracellular matrix protein $\mathrm{SC} 1$ coincides with synaptogenesis during rat postnatal development. Neurochem Res 33:1692-1700

Lively S, Brown IR (2008b) Extracellular matrix protein SC1/hevin in the hippocampus following pilocarpine-induced status epilepticus. J Neurochem 107:1335-1346

McKinnon PJ, Margolskee RF (1996) SC1: a marker for astrocytes in the adult rodent brain is upregulated during reactive astrocytosis. Brain Res 709:27-36

McKinnon PJ, McLaughlin SK, Kapsetaki M, Margolskee RF (2000) Extracellular matrix-associated protein $\mathrm{Sc} 1$ is not essential for mouse development. Mol Cell Biol 20:656-660

Mendis DB, Shahin S, Gurd JW, Brown IR (1994) Developmental expression in the rat cerebellum of $\mathrm{SC} 1$, a putative brain extracellular matrix glycoprotein related to SPARC. Brain Res 633:197-205

Mendis DB, Malaval L, Brown IR (1995) SPARC, an extracellular matrix glycoprotein containing the follistatin module, is expressed by astrocytes in synaptic enriched regions of the adult brain. Brain Res 676:69-79

Mendis DB, Ivy GO, Brown IR (1996a) SC1, a brain extracellular matrix glycoprotein related to SPARC and follistatin, is expressed by rat cerebellar astrocytes following injury and during development. Brain Res 730:95-106

Mendis DB, Shahin S, Gurd JW, Brown IR (1996b) SC1, a SPARCrelated glycoprotein, exhibits features of an ECM component in the developing and adult brain. Brain Res 713:53-63

Mendis DB, Ivy GO, Brown IR (1998) SPARC/osteonectin mRNA is induced in blood vessels following injury to the adult rat cerebral cortex. Neurochem Res 23:1117-1123

Mendis DB, Ivy GO, Brown IR (2000) Induction of SC1 mRNA encoding a brain extracellular matrix glycoprotein related to SPARC following lesioning of the adult rat forebrain. Neurochem Res 25:1637-1644

Menon PM, Gutierrez JA, Rempel SA (2000) A study of SPARC and vitronectin localization and expression in pediatric and adult gliomas: high SPARC secretion correlates with decreased migration on vitronectin. Int J Oncol 17:683-693

Meyer-Franke A, Kaplan MR, Pfrieger FW, Barres BA (1995) Characterization of the signaling interactions that promote the 
survival and growth of developing retinal ganglion cells in culture. Neuron 15:805-819

O'Shea KS, Dixit VM (1988) Unique distribution of the extracellular matrix component thrombospondin in the developing mouse embryo. J Cell Biol 107:2737-2748

O'Shea KS, Liu LH, Kinnunen LH, Dixit VM (1990a) Role of the extracellular matrix protein thrombospondin in the early development of the mouse embryo. J Cell Biol 111:2713-2723

O'Shea KS, Rheinheimer JS, Dixit VM (1990b) Deposition and role of thrombospondin in the histogenesis of the cerebellar cortex. J Cell Biol 110:1275-1283

Patton BL (2003) Basal lamina and the organization of neuromuscular synapses. J Neurocytol 32:883-903

Pfrieger FW, Barres BA (1997) Synaptic efficacy enhanced by glial cells in vitro. Science 277:1684-1687

Schultz C, Lemke N, Ge S, Golembieski WA, Rempel SA (2002) Secreted protein acidic and rich in cysteine promotes glioma invasion and delays tumor growth in vivo. Cancer Res 62:6270 6277
Shaham S (2006) Glia-neuron interactions in the nervous system of Caenorhabditis elegans. Curr Opin Neurobiol 16:522-528

Tran MD, Neary JT (2006) Purinergic signaling induces thrombospondin-1 expression in astrocytes. Proc Natl Acad Sci U S A 103:9321-9326

Ullian EM, Sapperstein SK, Christopherson KS, Barres BA (2001) Control of synapse number by glia. Science 291:657-661

Ullian EM, Christopherson KS, Barres BA (2004) Role for glia in synaptogenesis. Glia 47:209-216

Valder CR, Liu JJ, Song YH, Luo ZD (2003) Coupling gene chip analyses and rat genetic variances in identifying potential target genes that may contribute to neuropathic allodynia development. J Neurochem 87:560-573

Van der Loos H, Woolsey TA (1973) Somatosensory cortex: structural alterations following early injury to sense organs. Science 179:395398

Vincent AJ, Lau PW, Roskams AJ (2008) SPARC is expressed by macroglia and microglia in the developing and mature nervous system. Dev Dyn 237:1449-1462 